\title{
Enhancing the Creep Resistance of Sn-9.0Zn-0.5Al Lead-Free Solder Alloy by Small Additions of Sb Element
}

\author{
E. A. Eid', Manal A. Ramadan², A. B. El Basaty ${ }^{3}$ \\ ${ }^{1}$ Basic Science Department, Higher Technological Institute, Ramadan, Egypt \\ ${ }^{2}$ Mechanical Engineering Department, Higher Technological Institute, Ramadan, Egypt \\ ${ }^{3}$ Basic Science Department, Faculty of Industrial Education, Helwan University, Cairo, Egypt \\ Email: ahmedelbasaty@techedu.helwan.edu.eg
}

How to cite this paper: Eid, E.A., Ramadan, M.A. and El Basaty, A.B. (2018) Enhancing the Creep Resistance of Sn-9.0Zn$0.5 \mathrm{Al}$ Lead-Free Solder Alloy by Small Additions of Sb Element. Engineering, 10, 21-34. https://doi.org/10.4236/eng.2018.101003

Received: December 23, 2017

Accepted: January 28, 2018

Published: January 31, 2018

Copyright $\odot 2018$ by authors and Scientific Research Publishing Inc. This work is licensed under the Creative Commons Attribution International License (CC BY 4.0).

http://creativecommons.org/licenses/by/4.0/

\section{cc) (i) Open Access}

\begin{abstract}
The creep phenomenon is considered as one of the most important deformation mechanisms under working conditions. The present study has examined the microstructure and creep properties of $\mathrm{Sn}-9.0 \mathrm{Zn}-0.5 \mathrm{Al}$ solder alloy after adding a small amount of Antimony (Sb). Nominal compositions of Sb additions were chosen to be $0,0.5,1.0$, and $1.5 \mathrm{wt} . \%$. The minimum strain rate was reduced for the $\mathrm{Sb}$ containing solder alloy. The stress exponents, $\mathrm{n}$, were found to be around 3.7 for all soldiers at $130^{\circ} \mathrm{C}$. The stress exponent increases as the temperature drops from $100^{\circ} \mathrm{C}$ to $50^{\circ} \mathrm{C}$, except for the $1.0 \% \mathrm{Sb}$ alloy, where $\mathrm{n} 5.3-6.1$ at all the temperature range $\left(\mathrm{T}=50^{\circ} \mathrm{C}, 100^{\circ} \mathrm{C}\right.$ and $\left.130^{\circ} \mathrm{C}\right)$. The results reveal that the $\mathrm{Sb}$-containing solder alloys have better creep resistance with greater ductility than the Sb-free alloy due to solid solution strengthening, and intermetallic compound SnSb particle hardening.
\end{abstract}

\section{Keywords}

Sn-Zn-Al-Sb Alloys, Lead Free Solders, Sb Addition, Creep Properties

\section{Introduction}

Sn-9Zn eutectic alloy has been considered as one of the candidate that can be replaced the $\mathrm{Sn}-37 \mathrm{~Pb}$ solder without increase of the operating temperature. Apart from its favorable melting temperature of solder alloys, $\mathrm{Sn}-9 \mathrm{Zn}$ alloy has better mechanical properties than the conventional $\mathrm{Sn}-\mathrm{Pb}$ solders [1] [2] [3], and a lower cost than other Lead-free solders alloys [4] [5]. Whenever such alloys are used for many electronic applications, they are subjected to yield many prob- 
lems, such as, the tendency of oxidation and poor wetting ability [5]. Therefore, the researchers tried to add a third element to overcome the shortfalls of Sn-9Zn alloy. Consequently, it is necessary to understand how the oxidation resistance, wettability, corrosion, melting temperature, and mechanical properties are changed because of the third alloying element addition.

For example, the third element suggesting adding to Sn-9Zn eutectic alloy are $\mathrm{Ag}$ [4] [5], Bi [6] [7], In [8], $\mathrm{Al} \mathrm{[9]} \mathrm{[10]} \mathrm{and} \mathrm{Ce} / \mathrm{La} \mathrm{[11]} \mathrm{[12].} \mathrm{For} \mathrm{instance,}$ McCormack and Jin [8] found that small additions of 5\% In can improve the ductility of Sn-Zn base solders. It was found also that the wetting characteristics are improved when Ag is added [5] [13]. Moreover, Kim et al. [6] found that with increasing of additional $\mathrm{Bi}$ content, the melting temperature decreased from $198.4^{\circ} \mathrm{C}$ to $186.1^{\circ} \mathrm{C}$. However, the alloys with a high Bi content need to be controlled because of the brittle nature of $\mathrm{Bi}$ and the strong tendency for segregation [6] [14]. Chen and $\mathrm{Li}$ [15] reported that adding $1.0 \mathrm{wt} \% \mathrm{Sb}$ into $\mathrm{Sn}$-Ag-Cu solder alloy could lower the activity of Sn by forming SnSb compound. They proposed that $\mathrm{SnSb}$ particle might be initially formed and finally dispersed in the molten solder to increase the nucleation rate and refine the grain size. It is further found in tensile tests that mechanical properties are improved when the solder matrix is evenly dispersed with intermetallic compound (IMC) and SbSn particles [15] [16] [17] [18] [19].

Recently, our group reveled that adding a small amount of $\mathrm{Sb}$ to the $\mathrm{Sn}-9 \mathrm{Zn}$ $0.5 \mathrm{Al}$ system refined the bulky needles of $\mathrm{Zn}$ as well as $\beta$-Sn matrix. In addition, it improved strengthen by solid solution hardening mechanism [3]. In same time, it is known that under the conventional operating conditions, the solder joints are exposed to aggressive thermo-mechanical cycling (TMC), with imposed shear strain under high homologous temperatures $T_{H}\left(T_{H}=T / T_{m}\right)$ [20]. Therefore, the creep phenomenon is considered as the most important deformation mechanism under working conditions. Additionally, the literatures have rare studies about the effect of $\mathrm{Sb}$ as an alloying element on the creep properties of Sn-Zn-Al solder system. Therefore, the present study focused on the effect of $\mathrm{Sb}$ alloying element on the reliability characteristics of Sn-9.0Zn-0.5Al solder alloy based on microstructural, and creep tensile properties. We have chosen small percentages of the $\mathrm{Sb}$ added to $\mathrm{Sn}-\mathrm{Zn}$-Al solder alloy to make a solid solution of $\mathrm{Sb}$ within $\mathrm{Sn}$ matrix, which enhanced the creep resistance and rapture time of our solder alloy [1] [3]. Within this scope, the creep tests were performed under constant applied stresses ranging from 15.6 to $29.3 \mathrm{MPa}$ at constant temperatures of $50^{\circ} \mathrm{C}, 100^{\circ} \mathrm{C}$, and $130^{\circ} \mathrm{C}$.

\section{Experimental Work}

Table 1 shows the chemical compositions of solders used in this study. Each solder was made with pure $\mathrm{Sn}, \mathrm{Zn}, \mathrm{Al}$ and $\mathrm{Sb}$ (purity 99.99\%). The constituent elements were melted in vacuum Pyrex tube and maintained at $150^{\circ} \mathrm{C}$ above their respective melting point for 20 minutes, then cast into steel mold, and 
Table 1. Compositions of the solder alloy (wt. \%).

\begin{tabular}{cccccc}
\hline Alloy & abbreviation & Sn & Zn & Al & Sb \\
\hline Sn-9.0Zn-0.5Al & SZA905 & Bal. & 9.02 & 0.51 & 0.00 \\
Sn-9.0Zn-0.5Al-0.5Sb & SZA-0.5Sb & Bal. & 9.01 & 0.50 & 0.51 \\
Sn-9.0Zn-0.5Al-1.0Sb & SZA-1.0Sb & Bal. & 9.02 & 0.52 & 1.03 \\
Sn-9.0Zn-0.5Al-1.5Sb & SZA-1.5Sb & Bal. & 9.02 & 0.52 & 1.52 \\
\hline
\end{tabular}

air-cooled to the room temperature. The air-cooling is equivalent to that adopted in the particle reflow process in industry. The cooling rate estimated by using a thermocouple placed in the center of solder. The ingots were cold drawn to wire samples of $8 \times 10^{-4} \mathrm{~m}$ in diameter and $5 \times 10^{-2} \mathrm{~m}$ length. To obtain stabilized microstructures, the alloy samples were aged at $130^{\circ} \mathrm{C}$ for 3 hours, and then slow cooled to room temperature. The as-solidified microstructure of the solders was investigated using X-ray diffraction (Philips Analytical X-Ray PW3710) and Nikon optical microscope, where the grain sizes was estimated using a linear intercept technique. Tensile creep tests were performed using homemade instrument, the resulting strain recorded as a function of time under constant applied stresses ranging from 15.6 to $29.3 \mathrm{MPa}$ at constant temperatures of $50^{\circ} \mathrm{C}, 100^{\circ} \mathrm{C}$, and $130^{\circ} \mathrm{C}$. The accuracy of temperature measurement is of the order $1^{\circ} \mathrm{C}$. Strain measurements were done with an accuracy of $1 \times 10^{-2} \mathrm{~mm}$.

\section{Results and Discussion}

\subsection{As-Solidified Microstructure}

Optical micrographs of specimens with varying $\mathrm{x} \% \mathrm{Sb}(\mathrm{x}=0,0.5,1.0$ and 1.5) contents are presented in Figure 1. The bright-gray area and dark-gray area in Figure 1 denotes the primary $\beta$-Sn phase and eutectic $(S n+Z n)$ networks, respectively. This result is consistent with binary-phase diagram of $\mathrm{Sn}-\mathrm{Zn}$, which shows a typical binary-eutectic phase diagram with no intermetallic compounds and limited solubility of the two elements in each phase [9]. Much coarser primary $\beta$-Sn grains can be found only in the Sn-9.0Zn-0.5Al (SZA905) alloy as shown in Figure 1(a). In addition, the microstructure of the Sb-free alloy is not uniform. The formation of fully individualized and spheroid grains occurred during solidification at cooling rate of $10^{\circ} \mathrm{C} / \mathrm{s}$. Similar microstructures are observed in some Lead-free solder alloys at earlier solidification rates of $12^{\circ} \mathrm{C} / \mathrm{s}$ and $10^{\circ} \mathrm{C} / \mathrm{s}$ in studies [17]. Figures 1 (b)-(d) show that the originally coarse $\beta$-Sn grains were refined which is due to the amount of Sb-addition in the Sn-9.0Zn-0.5\% Al alloy. The addition of Sb promotes the formation of an equated array of grains with a wavy or curved phase boundaries. Figure 1(c) also reveals that the reduction in the grain size is most effective as $\mathrm{Sb}$ content up to $1.0 \%$. Therefore, it is assumed from the microstructure that the amount of $\mathrm{Sb}$ dissolved in Sn rich phase varies depending on the Sn-9.0Zn-0.5Al-xSb solder composition. According to phase diagram analysis and work done by other 


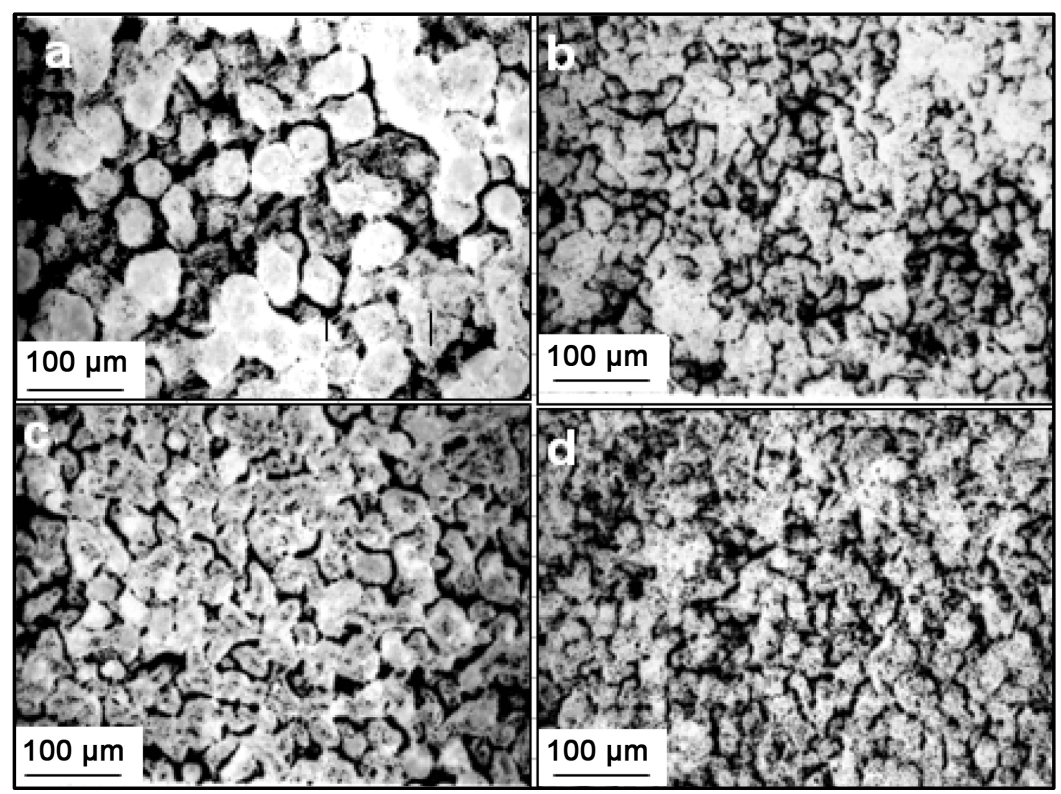

Figure 1. Optical images of the four solder alloys microstructure after annealing at $13^{\circ} \mathrm{C}$ for $3 \mathrm{~h}$ of composition (a) Sn-9.0Zn-0.5Al, (b) Sn-9.0Zn-0.5Al-0.5Sb, (c) Sn-9.0Zn-0.5Al-1.0Sb, and (d) Sn-9.0Zn-0.5Al-1.5Sb.

authors [2] [18] [21] [22] [23] [24], at a temperature above $234.8^{\circ} \mathrm{C}$, the presence of $\mathrm{Sb}$ in $\mathrm{Sn}-\mathrm{Zn}$ eutectic seems to simulate the formation of $\mathrm{SnSb}$ intermetallic compound (IMC) in molten solder. The SnSb phase is a stable phase and exists in the form of small particles that are finally dispersed in the matrix phase [23], which offers preferred sites for nucleation, resulting in grain refining and uniform microstructure as reported in our previous work [3].

The XRD micrographs for Sn-9.0Zn-0.5Al-x Sb\% $(\mathrm{x}=0.0,0.5,1.0$ and 1.5 wt \%) lead free solder alloys are depicted in Figure 2. Presence of (200), (101), (211) and (321) peaks at $2 \theta$ values of $31.2^{\circ}, 33.6^{\circ}, 45.3^{\circ}$, and $64.8^{\circ}$ respectively, confirm the formation of body centered tetragonal (BCT) crystal structure of $\beta$-Sn for all investigated alloys. Meanwhile, the XRD patterns of Sb-containing alloys exhibited obviously decrement in intensity of (002) and (100) of Zn crystallographic textures. The latter observation is detail discussed in our pervious article, which confirmed hypoeutectic composition is formed [3]. On other hand, no peaks of $\mathrm{Al}$ element were observed while SbSn IMC phase was detected as a small peak for $1.5 \mathrm{wt} \% \mathrm{Sb}$-content solder. That indicated the $\mathrm{Sb}$ atoms have successfully replaced the corresponding position of $\mathrm{Sn}$ atoms at BCT lattice sites for SZA-1.5 Sb lead free solder alloys [24].

\subsection{Features of Creep Behavior}

Figures 3(a)-(c) show the results of creep test obtained for Sn-9.0Zn-0.5Al-xSb $(\mathrm{x}=0.0 \%, 0.5 \%, 1.0 \%$, and $1.5 \%)$ solder alloys. The samples were investigated at temperatures of $50^{\circ} \mathrm{C}, 100^{\circ} \mathrm{C}$, and $130^{\circ} \mathrm{C}$ under different constant stresses $(15.6$ 29.3 MPa). The trend in the creep curves at all levels of applied stresses and temperatures suggests a rapid transition from a little primary creep regime, to an extended period of constant strain rate with tertiary creep regime. This transition 


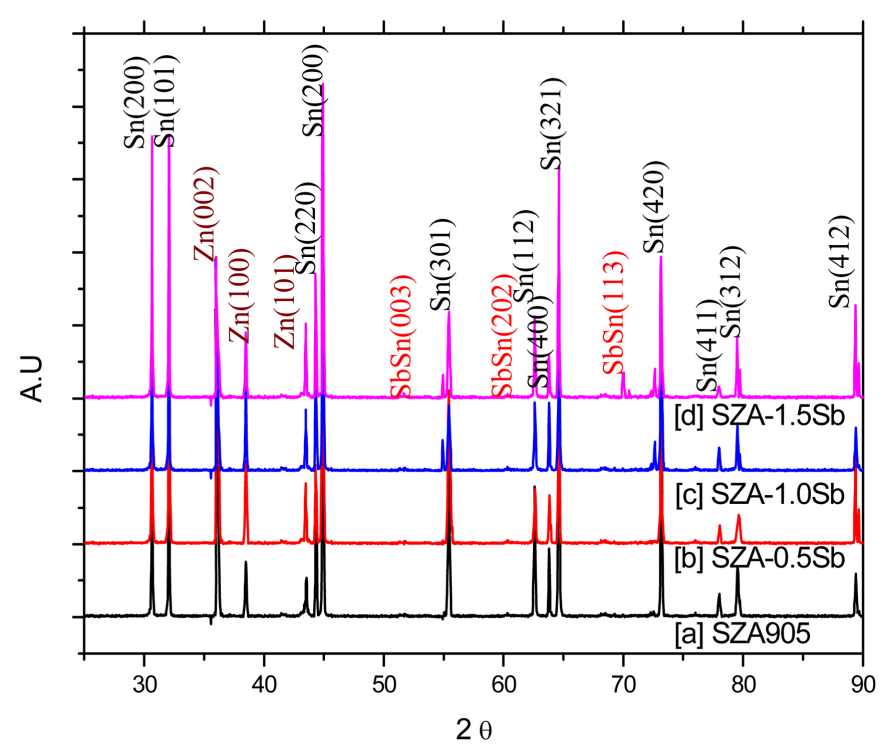

Figure 2. XRD patterns for as-solidified solder alloys (a) Sn-9.0Zn0.5Al, (b) Sn-9.0Zn-0.5Al-0.5Sb, (c) Sn-9.0Zn-0.5Al-1.0Sb and (d) Sn-9.0Zn-0.5Al-1.5Sb.

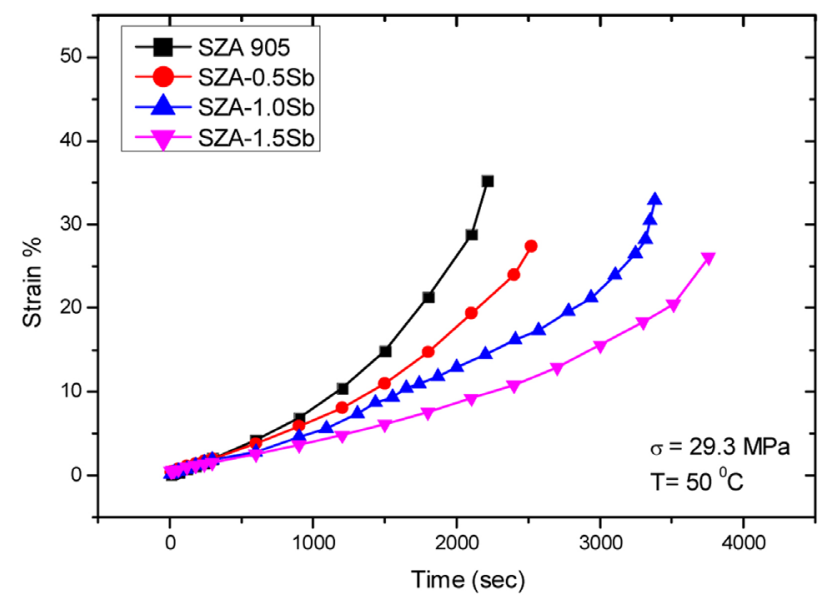

(a)

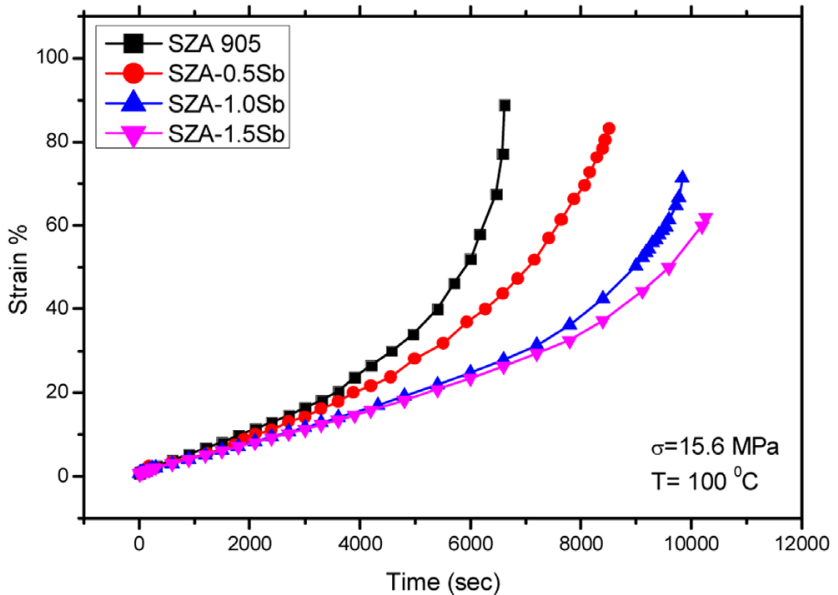

(b)

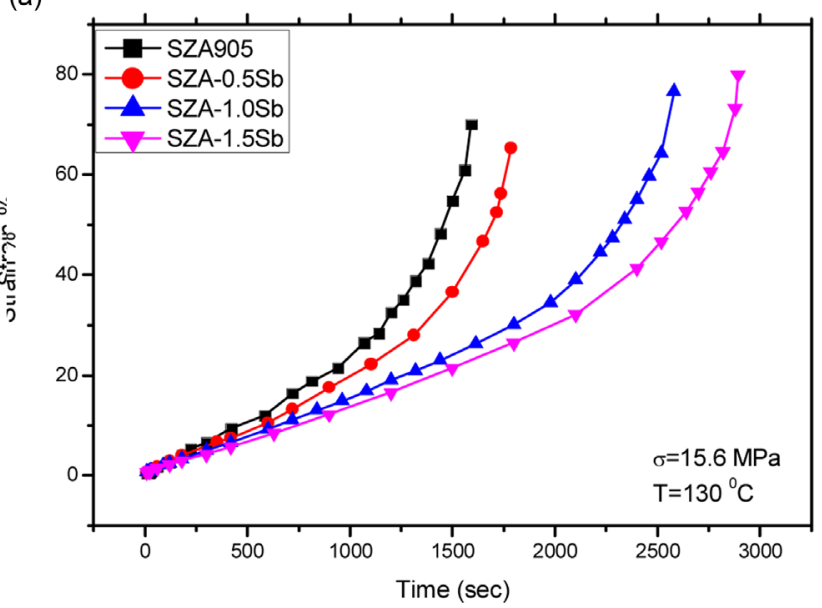

(c)

Figure 3. Comparison of the creep behavior of the four solder alloys under different stress at (a) $50^{\circ} \mathrm{C}$, (b) $100^{\circ} \mathrm{C}$ and (c) $130^{\circ} \mathrm{C}$. 
is easier to observe in the plot of strain rate versus time that is presented in Figure 4(a) and Figure 4(b). The materials showed characteristics of secondary and tertiary creep after loading with very little primary creep. Since the stress and temperature are constants, the variation in creep strain rate suggests a basic change in the internal structure of the alloy during time. The strain hardening in the primary creep was rapidly recovered and balanced in the steady state stage. However, effects of $\mathrm{Sb}$ addition on the creep curves are also presented in Figures 3-5. Additions of Sb not only reduced the strain rate but also increased the rapture

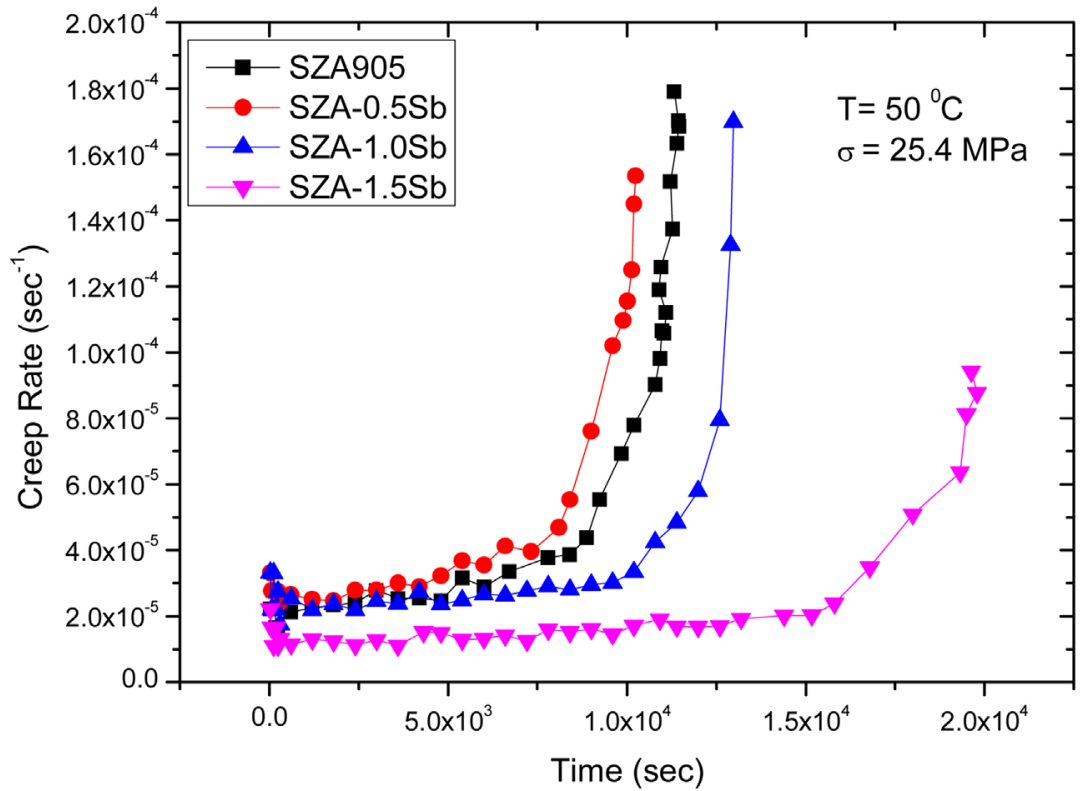

(a)

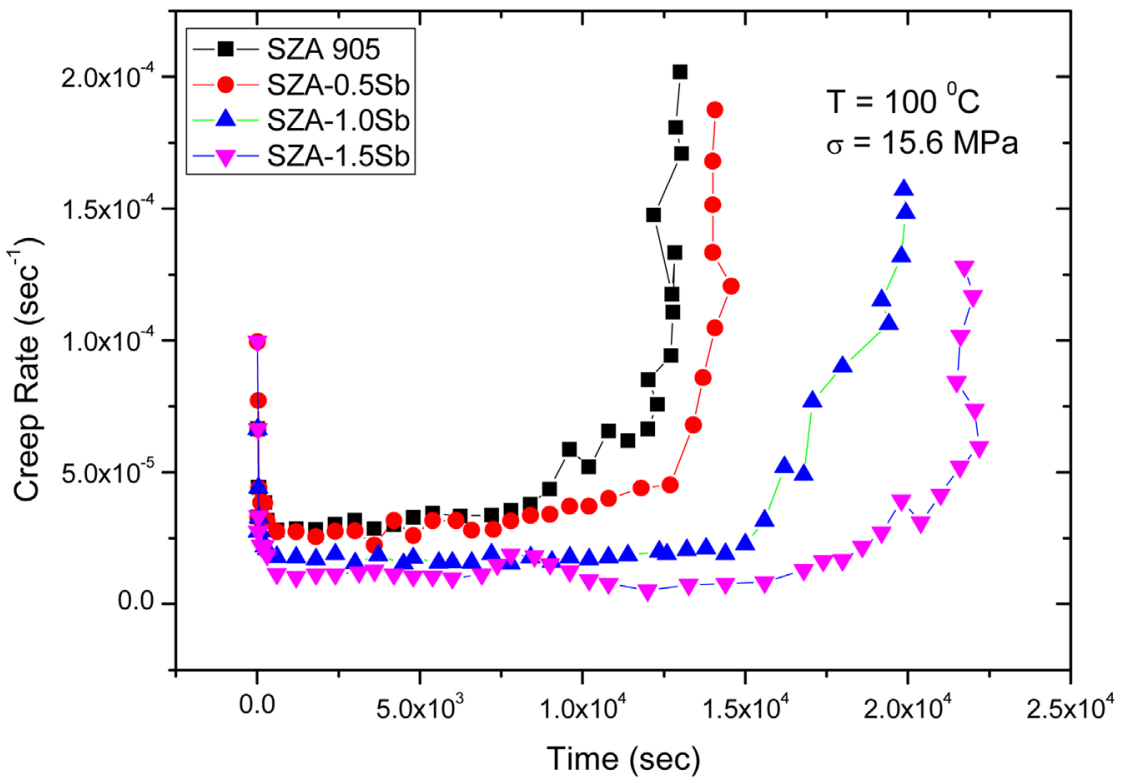

(b)

Figure 4. Creep rate-time curve of the $\mathrm{Sn}-9.0 \mathrm{Zn}-0.5 \mathrm{Al}-\mathrm{x} \mathrm{Sb} \%$ lead free solder alloys at (a) $\mathrm{T}=50^{\circ} \mathrm{C}$ and $(\mathrm{b}) \mathrm{T}=100^{\circ} \mathrm{C}$. 


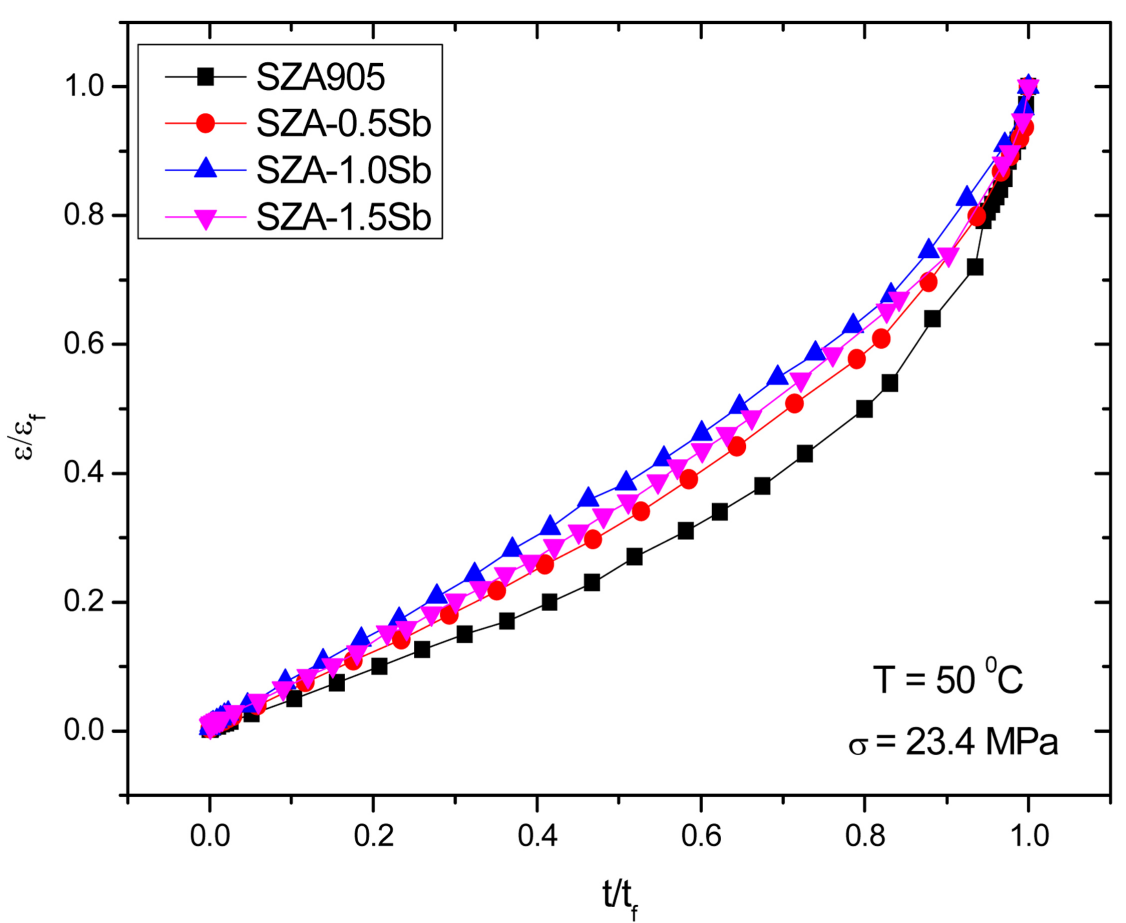

(a)

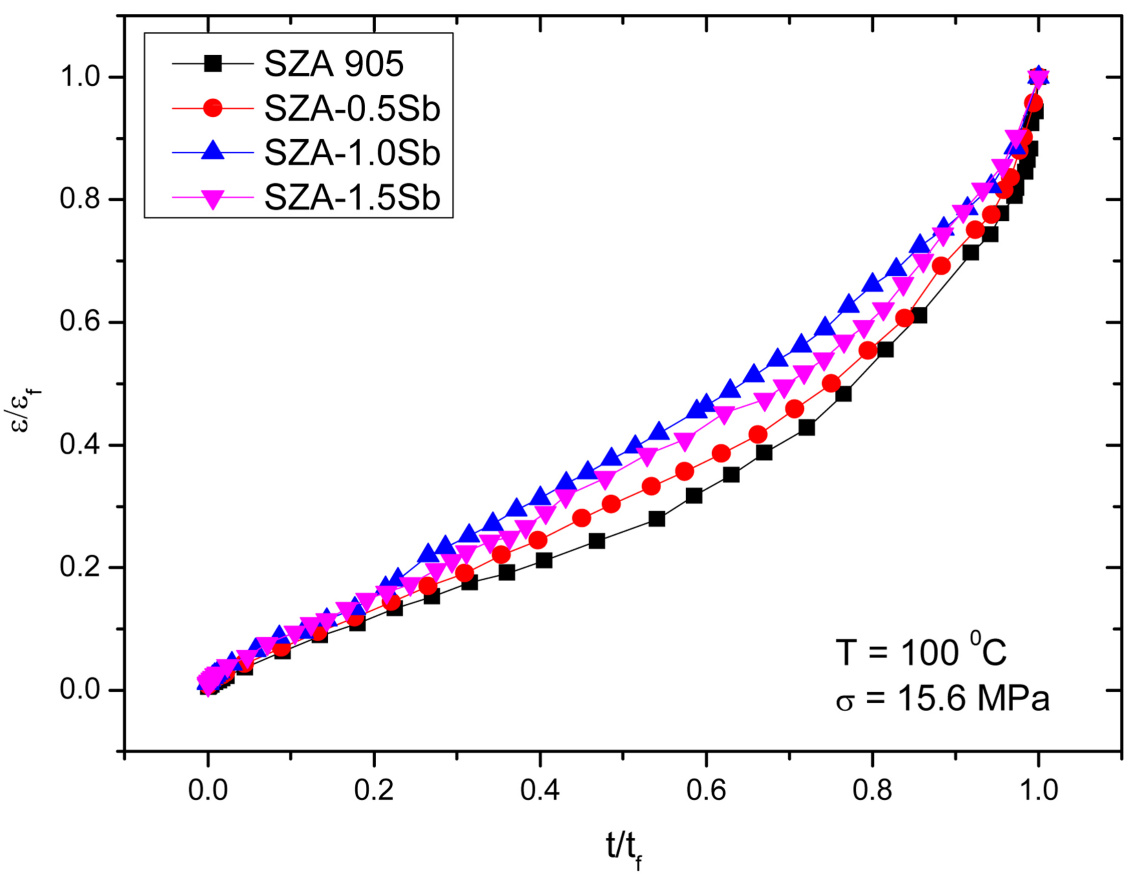

(b)

Figure 5. Normalized creep curve of Sn-9.0Zn-0.5Al-x Sb\% at (a) $\mathrm{T}=50^{\circ} \mathrm{C}$ and (b) $\mathrm{T}=$ $100^{\circ} \mathrm{C}$.

time, and the significant effect was at Sb content $1.0 \%$.

The specific features of the creep for the four alloys at temperatures of 50 and $100^{\circ} \mathrm{C}$ are compared in Figure 5(a) and Figure 5(b), in which creep strain $(\varepsilon)$ and time $(\mathrm{t})$ are normalized with respect to the rupture strain $\left(\varepsilon_{f}\right)$ and rupture 
time $\left(\tau_{f}\right)$, respectively. At $50^{\circ} \mathrm{C}$, the fraction of the steady-state creep strain increased against the rupture strain $\left(\varepsilon_{s} / \varepsilon_{f}\right)$ because of $\mathrm{Sb}$ additions, and that effect was maximized at $1.0 \% \mathrm{Sb}$. Whereas increasing the temperature from $50^{\circ} \mathrm{C}$ to $100^{\circ} \mathrm{C}$ resulted in decreasing the fraction $\left(\varepsilon_{s} / \varepsilon_{f}\right)$ for the $1.0 \% \mathrm{Sb}$ alloy and enhanced the creep resistance (i.e., lowered) which is associated with the dissolution of $\mathrm{Sb}$ rich $\beta$-Sn phase in the matrix [25].

\subsection{Stress Dependence of Minimum Creep Rate}

The minimum strain rate was measured as a function of stress and temperature from the linear portions of the creep curves for the four solder compositions. Stress exponents, n, were calculated from the power-law creep expression, $\dot{\varepsilon}_{\text {min }}$ $\sim \sigma_{\mathrm{n}}$, where $\dot{\varepsilon}_{\min }$ is the minimum creep rate and $\sigma$ is the applied stress. Log-Log plots of the minimum strain rate as a function of stress for the four solder alloys are given in Figures 6(a)-(d). The calculated values of $n$ from the data in Figure 6 are plotted versus temperature in Figure 7. The 1.0\% Sb alloy showed the best
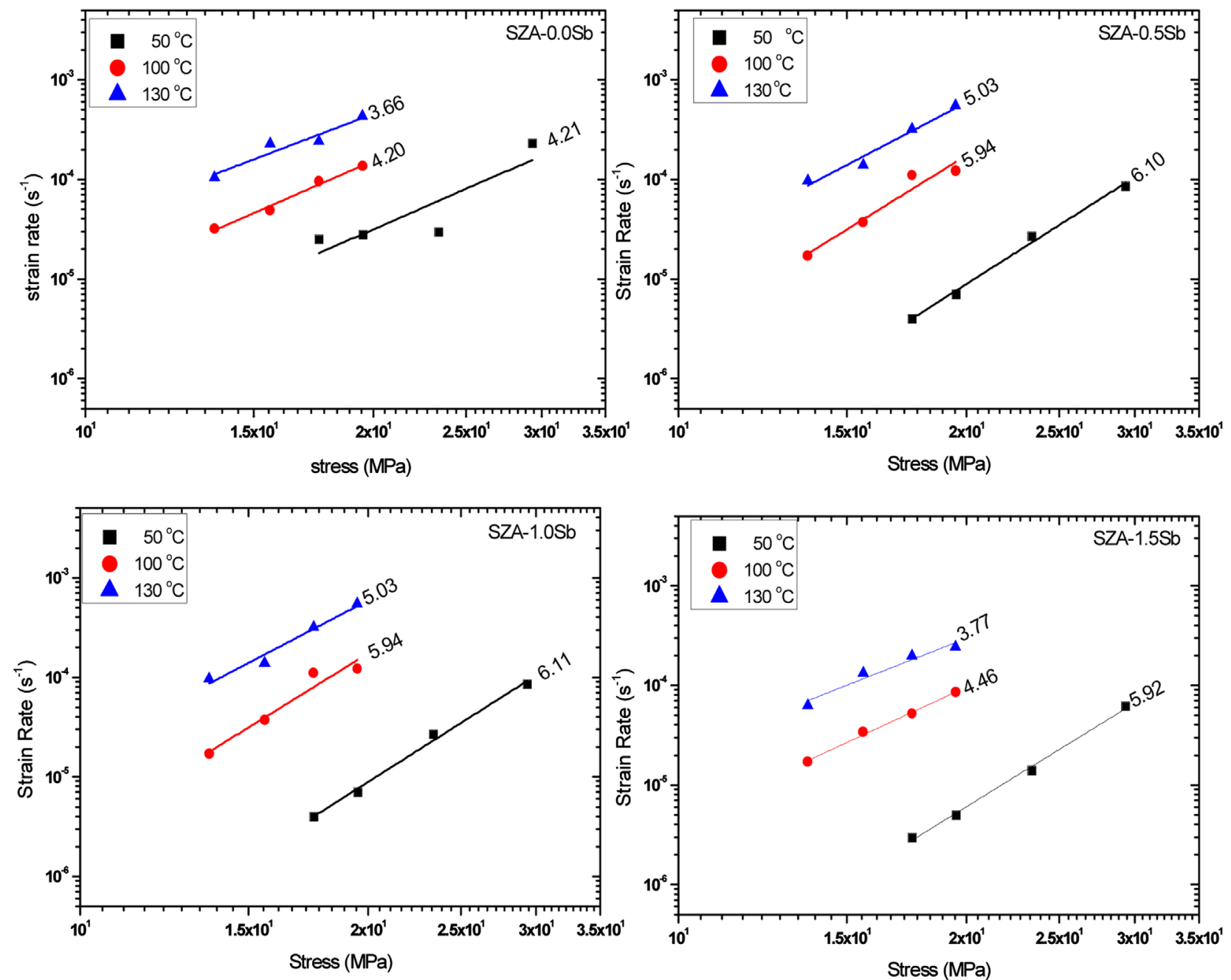

Figure 6. Steady-state creep rate $\dot{\varepsilon}$, plotted against applied stresses, $\sigma$, at various temperatures, $\mathrm{T}$, in double logarithmic scales of the four solder alloys. 


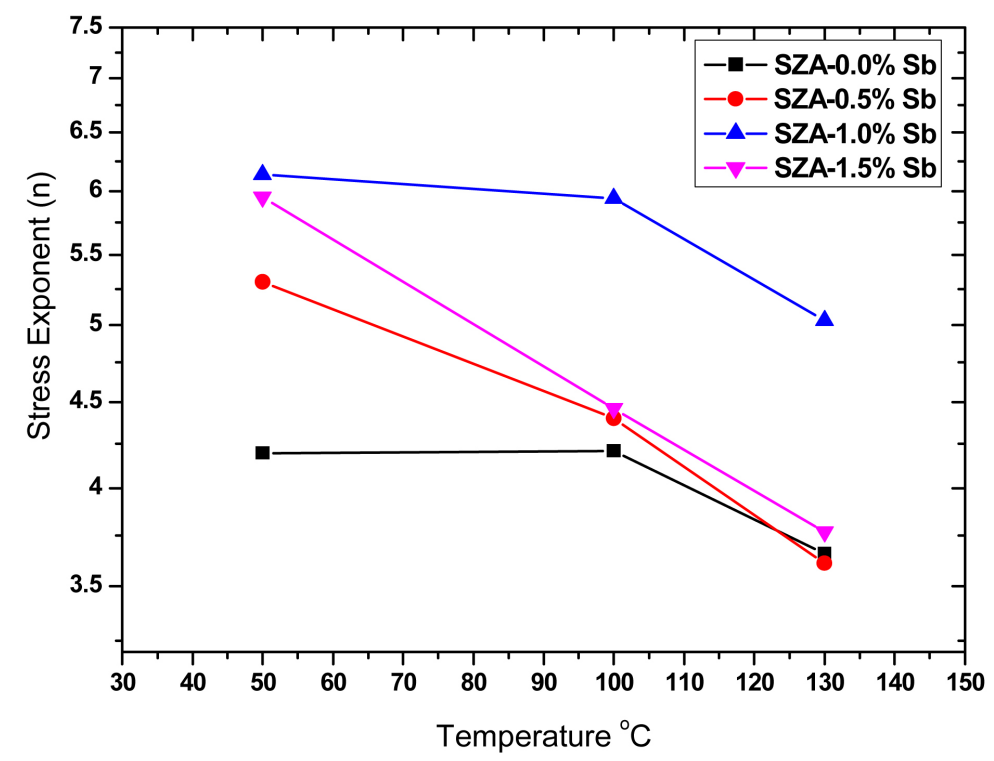

Figure 7. Stress exponent, n, dependence of temperature for investigated solders alloys.

creep resistance at all the temperature range, while the $\mathrm{Sb}$-free alloy showed the worst one. The major anomaly in the data is in the temperature dependence of stress exponent. At $130^{\circ} \mathrm{C}, \mathrm{n}$ values were usually around 3.7 for all solder alloys except for $1.0 \% \mathrm{Sb}$ specimens, which showed high $\mathrm{n}$ value of 5.3. The values of stress exponents for all solder alloys increase rapidly as the temperature decreases from $100^{\circ} \mathrm{C}$ to $50^{\circ} \mathrm{C}$, except the $1.0 \% \mathrm{Sb}$ alloy which showed almost identical stress exponent of $5.3-6.1$ at $50^{\circ} \mathrm{C}$ and $100^{\circ} \mathrm{C}$, a range of significant technological interest.

It appears that the amount of $\mathrm{Sb}$ dissolved in the solution-strengthened matrix phase varies with different $\mathrm{Sn}-9.0 \mathrm{Zn}-0.5 \mathrm{Al}$ solder systems. It is assumed that the stable characteristics of mechanical properties resulted in the strengthening effect of the solute concentration [2] [18] [22]. Sb element has higher affinity to the constituent element of $\mathrm{Sn}$ in the $\mathrm{Sn}-\mathrm{Zn}-\mathrm{Al}-\mathrm{Sb}$ quaternary system. It will reduce the activity of Sn by forming solid solution hardening and particle hardening of $\mathrm{Sb}$ rich $\beta$-Sn phase, resulting in refinement of the grain size, and thus improved the creep resistance as reported by Chen et al. [15]. However, the change in creep behavior with temperature is consistent with the observations of Song and Morris [21], Breen and Weertman [26], Suh et al. [27], and Poirie [28]. They noted significant changes in creep behavior of Sn-rich solders at about $100^{\circ} \mathrm{C}$. The data presented in Figure 7 show the range of stress exponent $(\mathrm{n} \sim 3.7-6.1)$ is comparable to that of Sn and Sn-rich solders, corresponding to climb-controlled creep ( $n \sim 4-5)$ reported by Breen and Weertman [26] and Song and Morris [21]. Dislocation climb-controlled creep is generally described by a power law equation of the form [22] [31]:

$$
\dot{\varepsilon}=A(\sigma)^{n} \exp (-Q / R T)
$$

where $A$ is a constant, $R$ is the gas constant, $n$ is the stress exponent and $Q$ is the 
activation energy. The apparent activation energy, $Q$, of the creep process was determined from Arrhenius plot ( $\log \dot{\varepsilon}$ versus 1/T), as shown in Figure 8, the values of, $Q$, for the process estimated to be $40 \pm 2 \mathrm{~kJ} /$ mole for Sb-containing solders and $\mathrm{Sb}$-free solder alloy as depicted in Figure 9, which are comparable to that reported for the pipe diffusion controlled climb of tin (43-46 kJ/mole) [29]

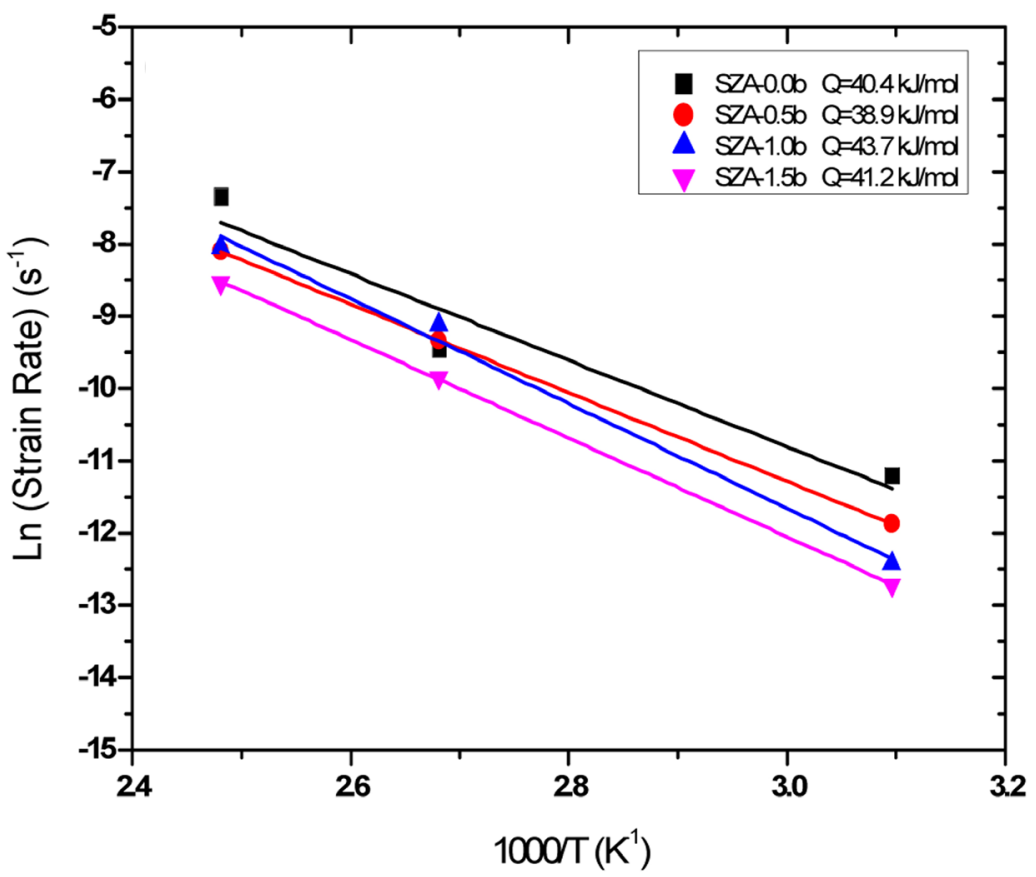

(a)

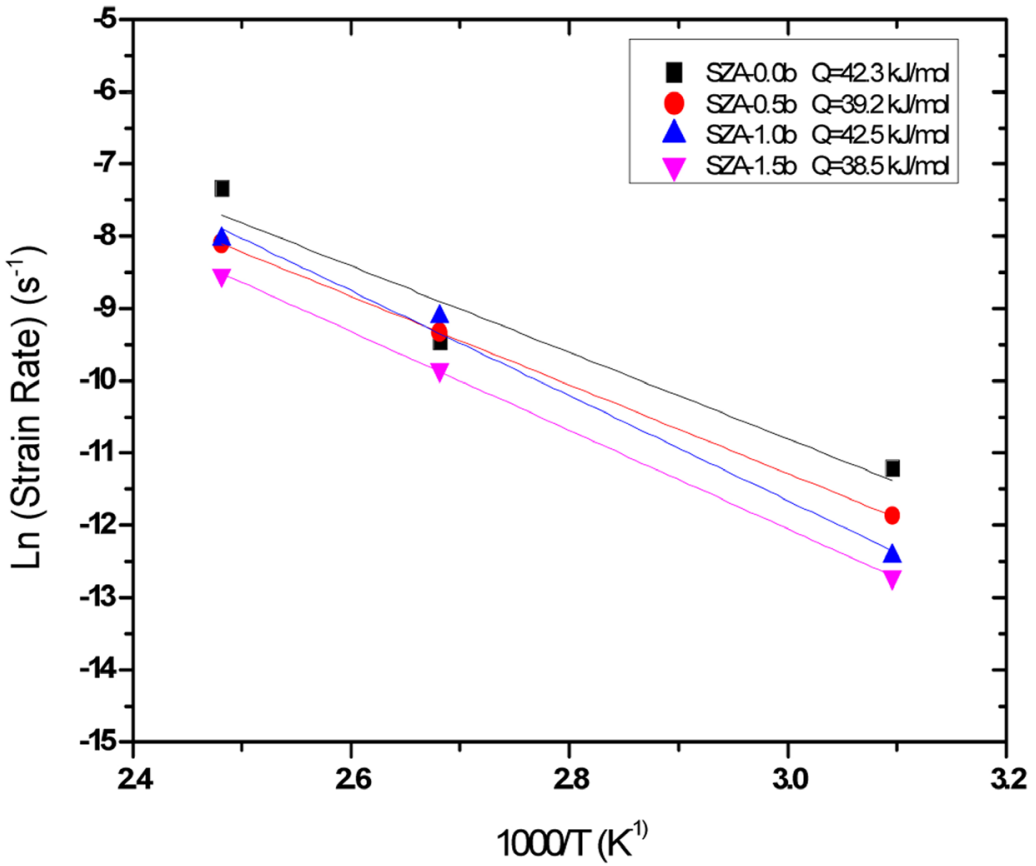

(b)

Figure 8. Effect of temperature on the steady-state creep rate of the four solder alloys at: (a) $\sigma=17.55 \mathrm{MPa}$, and (b) $\sigma=19.50 \mathrm{MPa}$. 


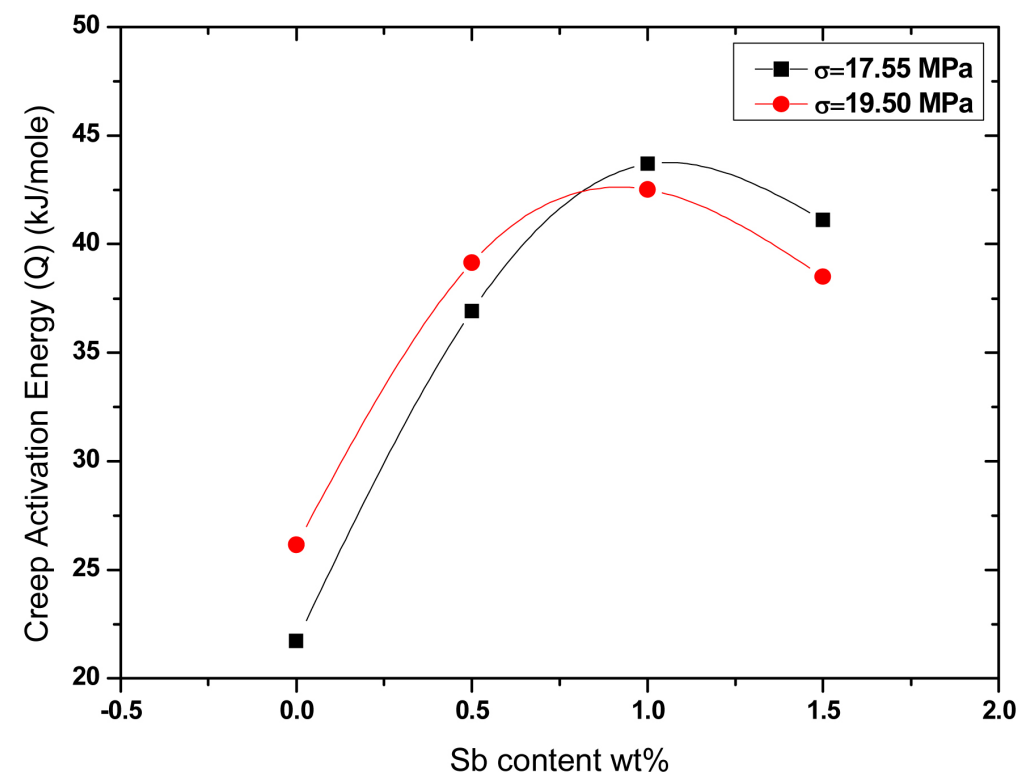

Figure 9. Activation energy dependence on the Sb content in Sn-8.9Zn-0.25Al solder alloys at different applied stress.

[30] [31]. From this analysis, no evidence for different creep mechanisms operating in the high and low temperature range was found. For more confirmation, the observed change in creep rates, $\dot{\varepsilon}_{\text {min }}$, between the $\mathrm{Sb}$-free solder and $\mathrm{Sb}$ containing solders clearly indicates the dominance of climb dislocation mechanism since diffusion creep would not be affected by the grain size in the present alloys. From these finding, one can seen that this low correlation between both the mechanical property data and the activation energies for the ternary Sn9.0Zn-0.5Al and the quaternary ternary $\mathrm{Sn}-9.0 \mathrm{Zn}-0.5 \mathrm{Al}-\mathrm{xSb}$ solder alloys leads to conclude that the crystallographic texture particularly in as-solidified solder plays an important role for determining the nature of creep deformation. This in turn, implies that the bulk inter-granular processes and dislocation movement are of high importance, particularly in the view of the main difference in the slip behavior of the constituent phases.

\section{Conclusions}

The main conclusions to be drawn from this study may be summarized as follows:

1) The originally coarse $\beta$-Sn grains in the microstructure of Sn-9.0Zn-0.5Al solder alloy were refined and become uniform after $\mathrm{Sb}$ additions due to the solute concentration and the finally dispersed SnSb particles in the matrix, which offer preferred sites for nucleation during solidification.

2) The Sb-containing solders have better creep resistance and greater ductility than the $\mathrm{Sn}-9.0 \mathrm{Zn}-0.5 \mathrm{Al}$ solder alloy, and the effect was usually found to reduce and increase rupture time $\tau_{f}$

3) The stress exponents were usually around 3.7 for all solders at $130^{\circ} \mathrm{C}$ except 
for $1.0 \mathrm{wt.} \% \mathrm{Sb}$ addition, which showed 5.3, and have a temperature dependence.

4) The activation energies for all compositions were estimated to be 40.2 $\mathrm{kJ} / \mathrm{mol}$, confirming pipe diffusion controlled climb of $\beta$-Sn.

\section{References}

[1] Abtew, M. and Selvaduray, G. (2000) Lead-Free Solders in Microelectronics. Materials Science and Engineering, 27, 95-141. https://doi.org/10.1016/S0927-796X(00)00010-3

[2] Puttlitz, K.J. and Stalter, K.A. (2004) Handbook of Lead-Free Solder Technology for Microelectronic Assemblies. Marcel Dekker, Inc., 292-294.

[3] El Basaty, A.B., Deghady, A.M. and Eid, E.A. (2017) Influence of Small Addition of Antimony (Sb) on Thermal Behavior, Microstructural and Tensile Properties of Sn-9.0Zn-0.5Al Pb-Free Solder Alloy. Materials Science and Engineering A, 701, 245-253. https://doi.org/10.1016/j.msea.2017.06.092

[4] Chang, T.C., Hon, M.H. and Wang, M.C. (2003) Intermetallic Compounds Formation and Interfacial Adhesion Strength of Sn-9Zn-0.5Ag Solder Alloy Hot-Dipped on Cu Substrate. Journal of Alloys and Compounds, 352, 168. https://doi.org/10.1016/S0925-8388(02)01122-2

[5] El-Daly, A.A., Swilem, Y., Makled, M.H., El-Shaarawy, M.G. and Abdraboh, A.M. (2009) Thermal and Mechanical Properties of Sn-Zn-Bi Lead-Free Solder Alloys. Journal of Alloys and Compounds, 484, 134-142. https://doi.org/10.1016/j.jallcom.2009.04.108

[6] Kim, Y.S., Kim, K.S., Hwang, C.W. and Suganuma, K. (2003) Effect of Composition and Cooling Rate on Microstructure and Tensile Properties of Sn-Zn-Bi Alloys. Journal of Alloys and Compounds, 352, 237. https://doi.org/10.1016/S0925-8388(02)01168-4

[7] Hirose, A., Yanagawa, H., Ide, E. and Kobayashi, K.F. (2004) Joint Strength and Interfacial Microstructure between $\mathrm{Sn}-\mathrm{Ag}-\mathrm{Cu}$ and $\mathrm{Sn}-\mathrm{Zn}$-Bi Solders and $\mathrm{Cu}$ Substrate. Science and Technology of Advanced Materials, 5, 267. https://doi.org/10.1016/j.stam.2003.10.024

[8] McCormack, M. and Jin, S. (1994) New Lead-Free Solders. Journal of Electronic Materials, 23, 635. https://doi.org/10.1007/BF02653349

[9] Lin, K.L., Wen, L.H. and Liu, T.P. (1998) The Microstructures of the Sn-Zn-Al Solder Alloys. Journal of Electronic Materials, 27, 97-105. https://doi.org/10.1007/s11664-998-0197-x

[10] Lin, K.L. and Wang, Y.C. (1998) Wetting Interaction of Pb-Free Sn-Zn-Al Solders on Metal Plated Substrate. Journal of Electronic Materials, 27, 1205. https://doi.org/10.1007/s11664-998-0070-y

[11] Wang, L., Yu, D.Q., Zhao, J. and Huang, M.L. (2002) Improvement of Wettability and Tensile Property in Sn-Ag-RE lead-Free Solder Alloy. Materials Letters, 56, 1039-1042. https://doi.org/10.1016/S0167-577X(02)00672-9

[12] Wu, C.M.L., Yu, D.Q., Law, C.M.T. and Wang, L. (2004) Properties of Lead-Free Solder Alloys with Rare Earth Element Additions. Materials Science and Engineering: R: Reports, 44, 1. https://doi.org/10.1016/j.mser.2004.01.001

[13] McMormack, M. and Jin, S. (1994) Improved Mechanical Properties in New, $\mathrm{Pb}$-Free Solder Alloys. Journal of Electronic Materials, 23, 715. https://doi.org/10.1007/BF02651364

[14] Date, M., Tu, K.N., Shoji, T., Fujiyoshi, M. and Soto, K. (2004) Interfacial Reactions 
and Impact Reliability of $\mathrm{Sn}-\mathrm{Zn}$ Solder Joints on $\mathrm{Cu}$ or Electroless $\mathrm{Au} / \mathrm{Ni}(\mathrm{P})$ Bond-Pads. Journal of Materials Research, 19, 2887. https://doi.org/10.1557/JMR.2004.0371

[15] Chen, B.L. and Li, G.Y. (2005) An Investigation of Effects of Sb on the Intermetallic Formation in Sn-3.5Ag-0.7Cu Solder Joints. IEEE Transactions on Components and Packaging Technologies, 28, 534-541. https://doi.org/10.1109/TCAPT.2005.848573

[16] Beshai, M.H.N., Habib, S.K., Yassein, A.M. and Saad, G. (1999) Effect of SnSb Particle Size on Creep Behaviour under Power Law Regime of Sn-10\%Sb Alloy. Crystal Research and Technology, 34, 119. https://doi.org/10.1002/(SICI)1521-4079(199901)34:1<119::AID-CRAT119>3.0.CO; $\underline{2-1}$

[17] Shohji, I., Yoshida, T., Takahashi, T. and Hioki, S. (2004) Tensile Properties of Sn-Ag Based Lead-Free Solders and Strain Rate Sensitivity. Materials Science and Engineering: $A$, 366, 50. https://doi.org/10.1016/j.msea.2003.09.057

[18] Chang, T.-C., Hon, M.-H., Wang, M.-C. and Lin, D.-Y. (2004) Effect of Thermal Cycling on the Adhesion Strength of Sn-9Zn-xAg-Cu Interface. IEEE Transactions on Advanced Packaging, 27, 158-164.

[19] Chen, B.L. and Li, G.Y. (2004) Influence of Sb on IMC Growth in Sn-Ag-Cu-Sb Pb-Free Solder Joints in Reflow Process. Thin Solid Films, 462, 395-401. https://doi.org/10.1016/j.tsf.2004.05.063

[20] Sarihan, V. (1993) Temperature Dependent Viscoplastic Simulation of Controlled Collaps under Thermal Cycling. Journal of Electronic Packaging, 115, 16. https://doi.org/10.1115/1.2909295

[21] Song, H.G., Morris Jr., J.W. and Hua, F. (2002) Anomalous Creep in Sn-Rich Solder Joints. Materials Transactions, 43, 1847.

[22] El-Daly, A.A. (2004) Tensile Properties of Pb-Sn Bearing Alloy Containing Small Amount of Sb. Physica Status Solidi (a), 201, 2035.

https://doi.org/10.1002/pssa.200306813

[23] Hansen, M. (1958) Constitution of Binary Alloys. McGraw-Hill Book INC, New York, 1217.

[24] Chang, T.C., Hon, M.H. and Wang, M.C. (2004) Electrochemical Behaviors of the Sn-9Zn-xAg Lead-Free Solders in a $3.5 \mathrm{wt} \% \mathrm{NaCl}$ Solution. Journal of the Electrochemical Society, 151, C484-C491. https://doi.org/10.1149/1.1756890

[25] Shin, S.W. and Yu, J. (2003) Creep Deformation of Lead-Free Sn-3.5Ag-Bi Solders. Japanese Journal of Applied Physics, 42, 1368. https://doi.org/10.1143/JJAP.42.1368

[26] Breen, J.E. and Weertman, J. (1955) Creep of Polycrystalline Tin. JOM: Journal of the Minerals, Metals, and Materials Society, 203, 1230. https://doi.org/10.1007/BF03379034

[27] Suh, S.H., Cohen, J.B. and Weertman, J. (1983) X-Ray Diffraction Study of Subgrain Misorientation during High Temperature Creep of Tin Single Crystals. Metallurgical Transactions $A, 14,117$. https://doi.org/10.1007/BF02643744

[28] Poirier, J.P. (1978) Is Power-Law Creep Diffusion-Controlled? Acta Metallurgica, 26, 629 .

[29] Igoshev, V.J. and Kleiman, J.I. (2000) Creep Phenomena in Lead-Free Solders. Journal of Electronic Materials, 29, 244. https://doi.org/10.1007/s11664-000-0150-0

[30] Reinikinen, T. and Kivilahti, J. (1999) Deformation Behavior of Dilute SnBi (0.5 to 6 at. pct) Solid Solutions. Metallurgical and Materials Transactions A, 30, 123. https://doi.org/10.1007/s11661-999-0200-Z 
[31] Eid, E.A., Fouda, A.N. and Duraia, E.-S.M. (2016) Effect of Adding 0.5 wt\% ZnO Nanoparticles, Temperature and Strain Rate on Tensile Properties of Sn-5.0 wt\% $\mathrm{Sb}-0.5$ wt\% Cu (SSC505) Lead Free Solder Alloy. Materials Science and Engineering: $A, 657,104-114$. https://doi.org/10.1016/j.msea.2016.01.081 